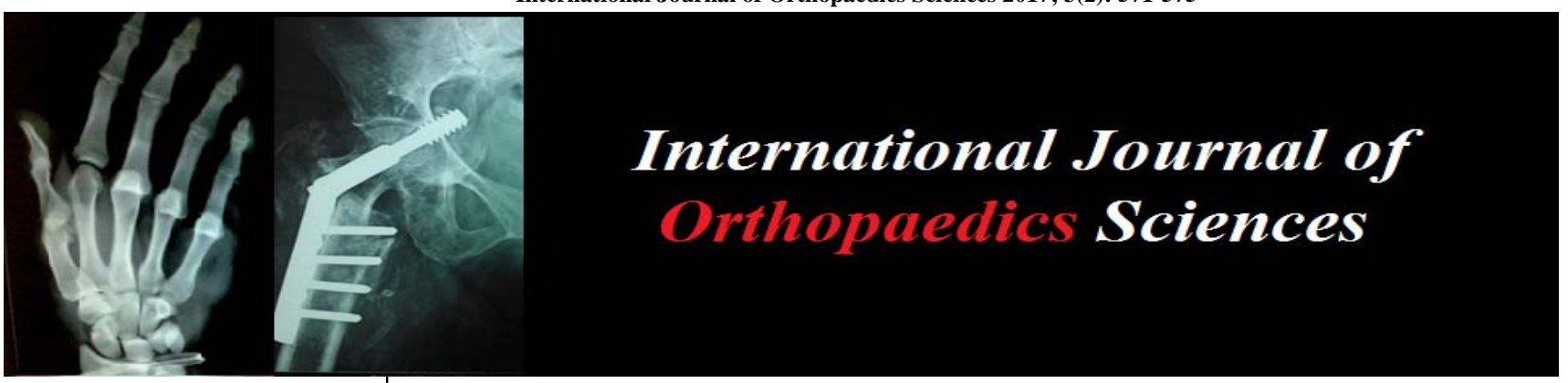

ISSN: $2395-1958$

IJOS 2017; 3(2): 571-575

(C) 2017 IJOS

www.orthopaper.com

Received: 23-02-2017

Accepted: 24-03-2017

Dr. Vivek P Nikumbha

M.S.Orthopaedics, BPT

Hospital, Mumbai, Maharashtra, India

Dr. G Krishna N Goud

D.Ortho, Resident Orthopaedics

Department, BPT hospital,

Mumbai, Maharashtra, India

Dr. Siddharth Baidya

Resident Orthopaedics

Department, BPT hospital,

Mumbai, Maharashtra, India

Dr. Kuldeep Mishra

Resident Orthopaedics

Department, BPT hospital,

Mumbai, Maharashtra, India

Correspondence

Dr. Vivek P Nikumbha

M.S.Orthopaedics, BPT

Hospital, Mumbai, Maharashtra,

India

\section{Prospective study of management of close or compound segmental fracture tibia by close reduction and internal fixation with interlocking nail}

\author{
Dr. Vivek P Nikumbha, Dr. G Krishna N Goud, Dr. Siddharth Baidya \\ and Dr. Kuldeep Mishra
}

DOI: $\underline{\text { http://dx.doi.org/10.22271/ortho.2017.v3.i2f.53 }}$

Abstract

Background: Fractures of tibia are rated as one among the list of common and major skeletal injuries as one third of its surface is subcutaneous. Segmental tibial fractures feature a unique fracture type characterized by a completely isolated intercalary osseous fragment separated by at least two different fracture lines. Since tibia is a large bone and one of the principal load bearing bones in the lower extremity, fractures can cause prolonged morbidity, extensive disability unless treatment is appropriate. Treatment of such fractures in adults is a challenge to orthopaedic surgeons due to its poor soft tissue coverage and poor blood supply. Moreover, compartment syndrome, neurovascular injuries and infection might add to the burden. Later non union, delayed union and Mal-union may occur. The acceptable treatment goal for the segmental fracture tibia is union maintaining normal length, normal alignment without rotational deformity, normal joint movements and reduced hospital stay. Interlocking nailing has proven to be the method of choice for fixation of these fractures. The intramedullary nailing under image intensifier fulfills the objective of stable fixation with minimal tissue damage resulting in better and quicker fracture unions.

Materials and methods: This study included 51 patients admitted in the Department of Orthopaedics with either open (37) or close segmental tibia fractures with compromised soft tissue (14) and treated with interlocking nail. Anterioposterior and lateral radiograph were done to diagnose fracture type. Routine preoperative investigation was followed. Patients were operated within 48 hours of hospital admission. Patients were followed up periodically on an outpatient basis on 2nd, 4th,

6 th, 10th, 14th, 18th week and 6th month. Clinical and radiological assessment was done for pain, deformity, shortening, range of motion of knee, ankle, subtalar joints and radiological union. The final outcome was assessed using Johner and Wruh's criteria

Results and Discussion: In our series, out of 51 cases, $47(92.15 \%)$ had acceptable Johner and wruth's criteria for functional results (sum of excellent and good results). Excellent in $36(70.59 \%)$, good in 11 $(21.57 \%)$, fair in $3(5.87 \%)$ and poor in 1 (1.97). These results were comparable with results btained by Ekeland and Alho who reported results excellent in 29, good in 13 and fair in 2 and poor in one out of 45 cases.

Conclusion: From this study, it was concluded that the preferred method of initial fracture stabilisation is the use of unreamed interlocking inramedullary tibial nail with immediate soft tissue cover whenever possible, this procedure require less surgical time, hospital stay, is cost effective and have minimum complications with good functional outcome.

Keywords: Management, compound segmental fracture tibia, close reduction, internal fixation, interlocking nail

\section{Introduction}

Fractures of tibia are rated as one among the list of common and major skeletal injuries as one third of its surface is subcutaneous. Segmental tibial fractures feature a unique fracture type characterized by a completely isolated intercalary osseous fragment separated by at least two different fracture lines. These type of fractures are mostly associated with high energy trauma and are therefore, often accompanied by substantial damage of the surrounding soft tissue and it is also associated with other injuries like fractures of other long bones, chest injuries and abdominal injuries. Since tibia is a large bone and one of the principal load bearing bones in the lower extremity, fractures can cause prolonged morbidity, extensive disability unless treatment is appropriate. 
Treatment of such fractures in adults is a challenge to orthopaedic surgeons due to its poor soft tissue coverage and poor blood supply. Moreover, compartment syndrome, neurovascular injuries and infection might add to the burden. Later non union, delayed union and Mal-union may occur. Segmental fractures are considered as separate clinical entity from the normal tibial fractures for number of reasons like, they are almost always caused by high-energy injuries, almost $50 \%$ are compound, they are often part of multiple injuries, they are frequently associated with sever soft tissue injuries, they have high complication rates, also their prognosis is often poor.

The acceptable treatment goal for the segmental fracture tibia is union maintaining normal length, normal alignment without rotational deformity, normal joint movements and reduced hospital stay. Current treatment options are locked intramedullary nailing, external fixators and plaster of Paris cast immobilization.

Boylston et al ${ }^{[1]}$ fifty years ago reviewed 28 patients and outlined treatment options for segmental tibial fractures. Options were: Cast immobilization, Rods, Plating, Rod and plate, Single screw, Fibular rod. These methods laid the foundation for the management of segmental tibial fractures.

Zucman and Maurer ${ }^{[2]}$ introduced the technique of unreamed tibial nailing in the management of both close and open segmental fractures. The unattainably perfect method of fracture treatment would safely fix the fracture so firmly that soft tissues and joints could be mobilized early and continuously during healing and when applicable, ambulation and weight bearing could be permitted. A method closely approaching this is medullary fixation. The use of IM nailing in the treatment of tibial shaft fractures has the following advantages: closed reduction and preservation of the periosteal blood supply, the possibility of early mobilisation of the knee and ankle joint, the ease with which the limb can be observed postoperatively, a lower prevalence of wound infections, good biomechanical stability of the cortical bone, good possibility for bone union, and a faster recovery and return to work.

The method of closed nailing without reaming followed by early ambulation and weight-bearing has positive advantages over all existing methods, significantly lower complication rate and has comparable results. Compared with A.O. technique it has the advantages of (1) not requiring specialized technique as complications following treatment with A.O. methods have been explained as due to insufficient expertise (2) not requiring special equipment and (3) being more suitable for high energy fractures (Bauer et al ${ }^{[3]}$, 1962; Edwards $\left.{ }^{[4]}, 1965\right)$.

Interlocking nailing has proven to be the method of choice for fixation of these fractures. The intramedullary nailing under image intensifier fulfills the objective of stable fixation with minimal tissue damage resulting in better and quicker fracture unions. The present study has been taken to review the results of segmental fractures of tibia treated with Intramedullary Interlocking nailing.

Aim: To study and evaluate the results and functional outcome of Interlocking intramedullary nailing in segmental fractures of tibia.

\section{Materials and methods}

This study was conducted between June 2012 to May 2014 in the Department of Orthopaedics, Dr.S.N. Medical College and Associated Group of Hospitals, Jodhpur, Rajasthan.51 patients were admitted in the Department of Orthopaedics with either open (37) or close segmental tibia fractures with compromised soft tissue (14) and treated with interlocking nail.

All patients were subjected to a detailed history and clinical examination with particular emphasis on mode of injury, time of injury, interval between injury and hospital admission and nature of treatment taken prior to admission.

Clinical examination was performed including general, systemic, neurovascular and local examination of injured part. Depending on nature of injury relevant radiological examination was done. If clinical examination indicates diminished distal pulses, further workup with ankle- brachial indices, doppler or angiogram was warranted, and should be the impetus for vascular consultation.

Anterioposterior and lateral radiograph were done to diagnose fracture type. Routine preoperative investigation was followed.

Open fractures were immediately irrigated, washed and temporarily immobilized with posterior POP above knee slab. Patients were operated within 48 hours of hospital admission.

Inclusion Criteria: All skeletally matured patients with open segmental tibial fractures (grade I to grade II Gustilo Aderson type) and all skelettaly matured patients with close segmental tibial fractures without soft tissue involvement, were included in the study.

Implants: A complete set of IL-nails from $28-38 \mathrm{~cm}$ length available in $8,9,10,11 \mathrm{~mm}$ diameter, hand/Power drill and drill bits of $3.2 \mathrm{~mm}$, locking screw set, hexagonal tipped screw driver, image intensifier television (IITV), flexible reamer and guide wire were used.

\section{Surgical Management}

Patient was operated within 48 hours of hospital admission. All open fractures were debrided and irrigated. The patient was positioned supine on a fracture table. Close intramedullary nailing was done without opening the fracture site and with or without reaming.

\section{Postoperative Care and Follow up}

Isometric quadriceps exercise and toes mobilization was started from second postoperative day. Regular weekly follow up was done to inspect wound condition and other complication for compound fractures and regular 2 weeks follow up for close fractures.

Passive knee mobilization exercise was started when pain and swelling subsided. Active range of motion (ROM) exercise was started after 3 days postoperatively in all patients. Serial radiographs were taken at 4 weeks interval.

Partial weight bearing was started after 21 days, Non weight bearing walking with the help of a walker started after 3 to 5 days and full weight bearing was started after 6 to 8 weeks depending upon the radiological appearance.

\section{Follow up and Assessment of final results}

Patients were followed up periodically on an outpatient basis on 2nd, 4th, 6th, 10th, 14th, 18th week and 6th month. Clinical and radiological assessment was done for pain, deformity, shortening, range of motion of knee, ankle, subtalar joints and radiological union.

The final outcome was assessed using Johner and Wruh's criteria ${ }^{[5]}$. 
Results

Table 1: Age Incidence

\begin{tabular}{|c|c|c|c|}
\hline S. No. & Age Group (yr) & No. of cases & Percentage \\
\hline 1 & $<20$ & 3 & 5.89 \\
\hline 2 & $21-30$ & 8 & 15.68 \\
\hline 3 & $31-40$ & 20 & 39.22 \\
\hline 4 & $41-50$ & 12 & 23.52 \\
\hline 5 & $51-60$ & 5 & 9.80 \\
\hline 6 & $>60$ & 3 & 5.89 \\
\hline & Total & 51 & 100 \\
\hline
\end{tabular}

Maximum number of patients (78. 42\%) were in age group 21 -50 years, with age ranging from 18 to 76 years. The mean age of patients under study was 40.6 years.

Table 2: Sex Incidence

\begin{tabular}{|c|c|c|c|}
\hline S. No. & Sex & No. of Patients & Percentage \\
\hline 1 & Male & 39 & 76.47 \\
\hline 2 & Female & 12 & 23.53 \\
\hline
\end{tabular}

Male female ratio of our series was 3.25:1 with males being involved almost three and a half times more than females.

Table 3: Mode of Injury

\begin{tabular}{|c|c|c|c|}
\hline S. No. & Mode of Injury & No. of cases & Percentage \\
\hline 1 & Road Traffic Accident & 44 & 86.27 \\
\hline 2 & Fall from Height & 5 & 9.80 \\
\hline 3 & Assault & 2 & 3.93 \\
\hline
\end{tabular}

Road traffic accident was the most common mode of injury accounting for $86.27 \%$ of the cases; assault was the cause of injury in only $3.93 \%$ of the cases.
Table 4: Side Involved

\begin{tabular}{|c|c|c|c|}
\hline S. No. & Side Involve & No. Of cases & Percentage \\
\hline 1 & Right & 32 & 62.74 \\
\hline 2 & Left & 19 & 37.26 \\
\hline
\end{tabular}

Right leg was involved in 32 cases, left leg in 19 cases.

Table 5: Open / close segmental tibial fracture with compromised soft tissue:

\begin{tabular}{|c|c|c|c|}
\hline S. No. & Type of injury & No of cases & Percentage \\
\hline 1 & Open fracture & 38 & 74.51 \\
\hline 2 & $\begin{array}{c}\text { Close fracture with } \\
\text { compromised tissue }\end{array}$ & 13 & 25.49 \\
\hline
\end{tabular}

In our series open proximal injury was present in $74.51 \%$ (38 cases) and close fracture with compromise soft tissue was present in $25.49 \%$ (13 cases).

Table 6: Associated injury

\begin{tabular}{|c|c|c|}
\hline S. No & Site of fracture & No. of cases \\
\hline 1 & Fracture femur & 3 \\
\hline 2 & Fracture patella & 4 \\
\hline 3 & Fracture pelvis & 2 \\
\hline 4 & Fracture forearm bone & 8 \\
\hline 5 & Fracture clavicle & 10 \\
\hline 6 & Head injury & 6 \\
\hline 7 & Chest injury & 2 \\
\hline
\end{tabular}

In our series most common associated injury was clavicle fracture in 8 cases.

Table 7: Post operative complication

\begin{tabular}{|c|c|c|c|c|c|c|c|}
\hline $\begin{array}{c}\text { No. of } \\
\text { cases }\end{array}$ & $\begin{array}{c}\text { Anterior } \\
\text { knee pain }\end{array}$ & $\begin{array}{c}\text { Superficial } \\
\text { infection }\end{array}$ & $\begin{array}{c}\text { Deep } \\
\text { infection }\end{array}$ & $\begin{array}{c}\text { Knee } \\
\text { stiffness }\end{array}$ & malunion & $\begin{array}{c}\text { Delayed } \\
\text { union/non union }\end{array}$ & $\begin{array}{c}\text { Shortening }> \\
\mathbf{1 c m}\end{array}$ \\
\hline 51 & 5 & 2 & 1 & 0 & 1 & 3 & 1 \\
\hline
\end{tabular}

Most common postoperative complication in over series was anterior knee pain in 5 cases. Superficial infection was found in 2 cases, deep infection in one case, malunion with valgus in a single case, delayed union in three cases that too in proximal and middle segment, shortening $>1 \mathrm{~cm}$ in one case and there was no case of knee stiffness.

\section{Final follow up}

Table 8: Extensor lag

\begin{tabular}{|c|c|c|c|}
\hline No of cases & Normal ext. & Extensor $\mathbf{l a g}<\mathbf{1 0}^{\mathbf{0}}$ & Extensor lag $>\mathbf{1 0}^{\mathbf{0}}$ \\
\hline 51 & 48 & 3 & 0 \\
\hline
\end{tabular}

Out of 51 cases, 48 had normal extension. 3 cases had extensor lag $<10^{0}$ while $>10^{\circ}$ extensor lag not seen in any patient.

Table 9: Range of motion (ROM) in knee joint

\begin{tabular}{|c|c|c|c|c|c|c|}
\hline No of cases & ROM more than $140^{\circ}$ & $\begin{array}{c}\text { ROM between } \\
120^{\circ} \text { to } 140^{\circ} \\
\end{array}$ & $\begin{array}{c}\text { ROM between } \\
90^{\circ} \text { to } 120^{\circ} \\
\end{array}$ & $\begin{array}{c}\text { ROM between } \\
60^{0} \text { to } 90^{\circ} \\
\end{array}$ & $\begin{array}{c}\text { Rom between } \\
30^{0} \text { to } 60^{0} \\
\end{array}$ & ROM less than $30^{\circ}$ \\
\hline 51 & 42 & 8 & 1 & 0 & 0 & 0 \\
\hline
\end{tabular}

In our series out of 51 cases, 42 cases had either full or more than $140^{\circ}$ range of motion, 8 had range of motion between $120^{\circ}$ to $140^{\circ}$, 1 case had range of motion between $90^{\circ}$ to $120^{\circ}$ and no patient with range of motion between $60^{\circ}$ to $90^{\circ}$. all patients had range of motion more than $90^{\circ}$ (acceptable).

Table 10: Angulation (varus / valgus)

\begin{tabular}{|c|c|c|c|c|}
\hline No. Of cases & Not present & $<\mathbf{1 0}^{\mathbf{0}}$ & $<\mathbf{1 0}^{\mathbf{0}}$ to $\mathbf{2 0}^{\mathbf{0}}$ & $>\mathbf{2 0}^{\mathbf{0}}$ \\
\hline 51 & 45 & 5 & 1 & 0 \\
\hline
\end{tabular}

In our series, no angulation was present in 45 cases. Angulation $<$ than $10^{\circ}$ was present in 5 cases, angulation in between $10^{0}$ to 20 was present in 1 case.

Table 11: Final results Johner and wruth's criteria for final results

\begin{tabular}{|c|c|c|c|c|}
\hline \multirow{2}{*}{ No. of cases } & \multicolumn{2}{|c|}{ Acceptable results } & \multicolumn{2}{c|}{ Unacceptable results } \\
\cline { 2 - 5 } & Excellent & Good & Fair & Poor \\
\hline 51 & 36 & 11 & 3 & 1 \\
\hline $100 \%$ & $70.59 \%$ & $21.57 \%$ & $5.87 \%$ & $1.97 \%$ \\
\hline
\end{tabular}


In our series out of 51 cases $47(92.15 \%)$ had acceptable functional results (sum of excellent and good results).

\section{Discussion}

The aim of the study was to evaluate the results of closed dynamic interlocking nailing in close and compound segmental tibial fractures.

The treatment programme should ensure a low incidence of complications; it should require minimum possíble interventions, short hospitalization and convalescence, and the end result should be comparable with the more complicated methods (Roíf Onnerflat, 1973).

The worst part of the study is that these injuries are encountered mainly in young males 21 to 50 years $(78.42 \%)$, who are the central pillar of the family.

Fractures of the tibia are the commonest among the major long bones fractures. Very often, they are open owing to the subcutaneous location of the tibia. The commonest cause of íhe fracture being hígh velocity road traffic accidents. ín our series $86.27 \%$ of the fractures groups were due to high velocity road traffic accidents

Due to the availabilííy of the new broad spectrum aníibiotics, the 'golden-period" of 6 hours can now safely be extended for compound fractures. This gives the treating surgeon adequate time to plan and tailor a suitable treatment regimen for a patient. With the use of new third generation Cephalosporin (Ceftriaxone), we were able to operate our cases presenting even as late seven days. This however, did nöt increase the infection rate as it appears.

Most of the authors used reamed iníerlocking nails viz. Olerud and Karlstrom ${ }^{[6,7]}$ (1972), Puno ét ál ${ }^{[8]}$ (1986), Klemn and Borner ${ }^{[9]}$ (1986), Ekeland ét ál ${ }^{[10]}$ (1993) and Renner et ál ${ }^{[11]}$ (1993) used unreamed tibial nail while Court-Brown ét al ${ }^{[12,13,14,15]}$ (1996) did a comparativé stüdy of reamed and unreamed nails. "Reaming resulted in the destruction of áll vessels of the medullary canal, rigid nailing with reamíng leads to a higher incidence of infection as dead bone produced due to reaming (debris/endosteal necrosis) acts as a good culture medium for bacteria (Bintcliffe et al [16, 17] 1984). While medullary nail without reaming caused minor damage to the blood supply.

Court Brown CM et al ${ }^{[12,13,14,15]}$ (1996) made a prospective study in 50 cases and concluded that reamed is better than unreamed nailing in tibial closed fractures. Blachut et al 11 concluded that there is a higher prevalence of delayed union and breakage of screws after nailing without reaming. Larsen et al (2004) studied 45 patients and concluded that the average time to fracture healingwas 16.7 weeks in reamed group and 25.7 weeks in the unreamed group. The difference was significant $(\mathrm{P}=0.004)$. Mohit Bhandari et al ${ }^{[18]}$ (2008) conducted a multicenter, blinded randomized trialof 1319 adults in whom a tibial shaft fracture was treated with either reamed or undreamed intramedullary nailing and demonstrated a possible benefit for reamed intramedullary nailing in patients with closed fractures. They found necrosis of the inner $50-70 \%$ of the cortex after reaming. In our study we used unreamed nail in 38 patients and reaming done in proximal segment in remaining 13 patients.

Interlocking was done by putting locking screws proximally $\&$ distally in áll of the cases.

Segmental fracture is considered by many to be a distinctive type of injury having difficult healing process ${ }^{[19]}$ and often associated with an increase severity of soft tissue injury.

In our study $74.51 \%$ patients were having open injury, this is in agreement with the study shown by Woll and Duwelius ${ }^{[20]}$ who have reported an incidence of $75 \%$ open fractures in this pattern of injury.

Boutin ${ }^{[21]}$ first described the poor prognosis of segmental tibial fractures and Charnley ${ }^{[22]}$ recognised the unsuitability of non-operative treatment in management of segmental fractures of tibia.

Many authors support and recommend fixation with intramedullary nailing ${ }^{[23]}$ with advent of interlocking nail provide superior results ${ }^{[24,25]}$.

Similar to our study and observations Ekeland ${ }^{[10]}$ and Alho ${ }^{[26]}$ examined 43 patients with segmental tibial fractures out of which they reported one non union, one deep and one superficial infection and finally they concluded that the interlocking nail proved to be efficient mode of treatment for comminuted segmental and unstable tibial fractures.

In our series 2 patients $(3.9 \%)$ had superficial wound infection of the proximal incísion síte. This responded to the usual oral antibiotics and daily dressings. One patient (1.96\%) had deep infection. Regular dressing, oral antibiotics and guarded weight bearing was continued till the fracture united (18 weeks). two cases had superficial infection were Gustilo's grade II. The injury surgery interval in one of these cases was 7days and the other 2 were 4-5 days (because of associated head injury). This delay in the surgery was the probable cause of superficial infection in two cases and deep infection in one case. This indicates that early surgery with a proper antibiotics cover is a must when considering a case of compound tibial fracture for nailing.

Sir Watson Jones (1982) ${ }^{[27]}$ said "what may be an ideal safe treatment in a first class and fully staffed trauma unit in Europe could be disastrous if employed in an underdeveloped country with very limited surgical services.'

We encountered 3 cases of delayed union in which, after waiting for about 16 weeks when abundant callus was not visible in the skiagram and the patient had persistent tenderness over the fracture site. Two of the cases had hypertrophic type of non-union. The reason in one of these cases was probably a deep infection due to improper hygiene and non compliance of the patient to follow the weight bearing protocol and other instructions and also lack of regular antibiotic intake. This indicates the importance of regular follow up and patients compliance.

The distal fracture is the usual site for the non-union, proposed reason for this being the direct injury to the soft tissue overlying this fracture and natural tendency to slow union in fractures at this location ${ }^{23}$.

Although other authors reported no significant difference in union rate at proximal and distal fracture sites. This is consistent with our results as in our study we got non union in two patients at proximal fracture site.

We had 30 cases of other associate injuries along with segmental tibial fractures. Out of them 10 clavicle fractures managed conservatively. 3 cases of femur fractures, 4 cases of patella fractures and 8 cases of fracture forearm bones were operated simultaneously, 2 cases pelvic injury managed conservatively and six cases of head injury out of which in three cases surgery was delayed till patient was fit for the same.

Most common postoperative complication was anterior knee pain in 5 patients. Occasional Pain in knee was a common problem in 32 patients, 5 patients had constant pain after activity. However the pain did not disturb the activities of daily living in majority of patients.

In our series out of 51 cases 47 (92.15\%) had acceptable Johner and wruth's criteria for functional results (sum of 
excellent and good results). Excellent in $36(70.59 \%)$, good in $11(21.57 \%)$, fair in $3(5.87 \%)$ and poor in 1 (1.97) Ekeland ${ }^{[10]}$ and Alho ${ }^{[26]}$ reported results excellent in 29, good in 13 and fair in 2 and poor in one out of 45 cases.

\section{Conclusion}

From the observation of present study it is concluded that the high-energy trauma associated with this pattern of injury poses many challenges to the surgeon due to the precarious blood supply of the intermediate segment and the serious damage to the surrounding soft tissues. The risk of non-union, delayed union, infection and additional procedures is high as seen in this series of patients. The preferred method of initial fracture stabilisation is the use of unreamed interlocking inramedullary tibial nail with immediate soft tissue cover whenever possible, this procedure require less surgical time, hospital stay, is cost effective and have minimum complications with good functional outcome.

\section{References}

1. Boylston BF, Milam R. Segmental fractures $f$ the Tibia: an analysis of thirty cases. Southern Medical Journal. 1957; 50:969-975.

2. Zucman J, Maurer P. Two-level fractures of the tibia. Results in thirty six cases treated by blind nailing. Journal of Bone and Joint Surgery. 1969; 51B:(4):686-693.

3. Bauer GCH, Eddwards P, Widmark PM. Shaft fracture of tibia. Etiology of poor results in a consecutive series of 173 fractures. Acta Chir. Scand, 1962; 124:286.

4. Edwards P. Fractures of the shaft of tibia: 492 consecutive cases in adults - importance of soft tissue injury. Acta. Orthop. Scan- Supple. 1965; 76:1.

5. Wruh O, Johner R. Classification of tibial shaft fractures and corellation with results after rigid fixation. Clinical Orthop. 1983, 178.

6. Olerud S, Karlstrom G. Tibial fractures treated by AO compression osteosynthesis - Experience from 5 years material. Acta. Orthop. Scan Supple. 1972; 140:1.

7. Olerud S, Karlstrom G. The spectrum of intramedullary nailisg of the tibia, Clin. Orthop, 1986; 212101.

8. Puno et al. Critical analysis of results of treatment of 201 tibial shaft tissue fractures. Clin. Orthop. 1986; 212:113.

9. Klemn, Borner. Interlocking nailing of complex fracture of femur and tibia. Clin Orthop. 1986; 212; 89.

10. Ekeland A, Stromsoe K et al. Locked Intramedullary Nailing for displaced tibial shaft fractures. J Bone Joint Surg. 1990, 805-809.

11. Renner $\mathrm{N}$ et al. Initial experience with undreamed tibial nail. Helv. Chir. Acta. 1993; 59:665.

12. Court Brown CM et al. Closed intramedullar/ nailing tibia- its use in closed \& type I open fracture, J.B.J.S. 1990a; 72 B:605.

13. Court Brown CM et al. Locked intramedullary nailing of open tibial fractures. J.B.J.S. 1991; 73B;959.

14. Court Brown $\mathrm{CM}$ et al. Infection after intramedullary nailing tibia. J.B.J.S. 1992; 74B:770.

15. Court Brown CM et al. Reamed or undreamed nailing for closed tibial fractures - A prospective study in Tscherne C1 fractures - JBJS 1996; 78B:580.

16. Bintciiffe, Vickers. Tibial nailing - in open or shut cases. JBJS. 1980; 62B:525.

17. Bintciiffe IW. The case of an open approach to tibial nailing. Injury. 1984; 15(6):407.

18. Mohit Bhandari et al. Randomized Trial of Reamed and Unreamed Intramedullary Nailing of Tibial Shaft
Fractures. J Bone Joint Surg Am. 2008; 90:2567-2578.

19. Rommens PM, Willy Coosemans, Broos PLO. The difficult healing of segmental fractures of the tibial shaft. Archives of orthopaedic and trauma surgery. 1989; 108(4):238-242.

20. The segmental tibial fracture Woll T.S., Duwelius P.J. () Clinical Orthopaedics and Related Research, 1992; 281:204-207.

21. Boutin P. 25 case de fractures bifocales de jambe Rev. Chir. Orthop. 1956; 42:647-663.

22. Charnley J. The closed treatment of common fractures. 3rd ed. London: Churchill Livingstone. 1972.

23. Intramedullary nailing in segmental tibial fractures Melis GC, Sotgiu F, Lepori M, Guido P. Journal of Bone and Joint Surgery - Series A. 1981; 63(8):13101318. Interlocking intramedullary nailing in the treatment of tibial fractures. A report of 45 cases

24. Ekeland A, Thoresen BO, Alho A, Stromsoe K, Folleras G, Haukebo A. Clinical Orthopaedics and Related Research, 1988; 231:205-215.

25. Huang CK, Chen WM, Chen TH, Lo WH. Segmental tibial fractures treated with interlocking nails. A retrospective study of 33 cases Acta Orthop. Scand., 1977; 68(6):563-566.

26. Alho A, Benterud JG, Hogevold HE et al. Comparison of functional bracing and locked medullary nailing treatment of displaced tibial fractures. Clin Orthop. 1992; (277):243-50.

27. Watson-Jones. Fractures and joints injuries. 6'h Edition, Churchill lvingstone, London, 1982. 